\title{
Erratum to: Scaling of the Temperature Dependent Resistivity and Hall Effect in $\mathrm{Ba}\left(\mathrm{Fe}_{1-x} \mathrm{Co}_{x}\right)_{2} \mathrm{As}_{2}$
}

\author{
E. Arushanov • S. Levcenko • G. Fuchs • B. Holzapfel • \\ S.L. Drechsler $\cdot$ L. Schultz
}

Published online: 29 July 2011

(C) Springer Science+Business Media, LLC 2011

\section{Erratum to: J Supercond Nov Magn}

DOI 10.1007/s10948-011-1198-1

In the title as well as along the text, figure captions and table $\mathrm{Ba}\left(\mathrm{Fe}_{1-x} \mathrm{Co}_{x}\right) \mathrm{As}_{2}$ should be replaced by $\mathrm{Ba}\left(\mathrm{Fe}_{1-x} \mathrm{Co}_{x}\right)_{2}$ $\mathrm{As}_{2}$. Although the results and conclusions of the paper are unaffected, the authors nonetheless regret this error.

The online version of the original article can be found under doi:10.1007/s10948-011-1198-1.

E. Arushanov · G. Fuchs · B. Holzapfel · S.L. Drechsler ·

L. Schultz

Leibniz-Institut für Festkörper- und Werkstoffforschung

Dresden-IFW Dresden, 01069 Dresden, Germany

E. Arushanov · S. Levcenko $(\bowtie)$

Institute of Applied Physics, Academy of Sciences of Moldova,

2028 Chisinau, Moldova

e-mail: levcenco@yandex.ru 